\title{
Electroporation ablation of bronchial smooth muscle cells: A novel non-thermal asthma therapy
}

\author{
Jason A. Tri ${ }^{2}$, Christopher V. DeSimone ${ }^{1}$, Craig Daniels ${ }^{4}$, Roshini S. Asirvatham ${ }^{2}$, Susan B. Mikell ${ }^{3}$, Dorothy J. Ladewig ${ }^{3}$, Kelly Krajnick ${ }^{3}$ \\ and Samuel J. Asirvatham ${ }^{1,5 *}$ \\ ${ }^{1}$ Division of Cardiovascular Diseases, Department of Internal Medicine, Mayo Clinic, Rochester, Minnesota, USA \\ ${ }^{2}$ Mayo Clinic Summer Externship Program, Mayo Clinic, Rochester, Minnesota, USA \\ ${ }^{3}$ Mayo Clinic Ventures, Mayo Clinic, Rochester, Minnesota, USA \\ ${ }^{4}$ Division of Pulmonary and Critical Care Medicine, Department of Internal Medicine, Mayo Clinic, Rochester, Minnesota, USA \\ ${ }^{5}$ Department of Pediatrics and Adolescent Medicine, Mayo Clinic, Rochester, Minnesota, USA
}

\begin{abstract}
Objective: Asthma is a common disease which places significant burden on the US healthcare system and which can be associated with significant patient morbidity and mortality. Current medical therapies are costly and not curative. A new approach for a more permanent asthma treatment is the use of radiofrequency ablation. However, this radiofrequency approach is thermal-based and can result in deleterious effects to the airways, such as stenosis or ulceration. We describe a novel, improved therapeutic approach for smooth muscle ablation using non-thermal DC electroporation ablation.

Methods: We developed and tested prototype electroporation ablation devices that access the airways both endoscopically and via a bronchoscope. We tested the feasibility of this approach and demonstrated proof-of-concept in 2 mongrel dogs. In order to assess for smooth muscle function, we performed functional studies pre and post ablation with methacholine challenge to assess for airway reversibility. We also evaluated bronchial lesions via direct vision with bronchoscopy.

Results: We developed novel electroporation catheters to delivery energy to the bronchial smooth muscle through an endoscopic approach. We tested these catheters in 2 acute canine studies and successfully demonstrated the ability to destroy smooth muscle tissue via novel prototypes and saline irrigation for widespread nonthermal electroporation ablation. Our functional studies demonstrate the efficacy of this approach.
\end{abstract}

Conclusion: We report a novel method for non-thermal bronchial smooth muscle ablation using novel prototypes and electroporation with normal saline. These early findings require further evaluation in larger, chronic canine studies to assess for use as a potential curative therapy.

\section{Introduction}

Asthma is a debilitating, chronic disease that affects about 30 million people in the United States alone [1]. The need for improved therapies for asthma is underscored by the fact that there are 180,000 deaths per year associated with this disease with the primary burden of morbidity disease in children [2].

Currently, there exists no cure for asthma. Present treatment modalities are designed to control this disease, rather than target the root of the pathophysiology of asthma: increased airflow resistance due to smooth muscle contractions $[2,3,5]$. The current standard for asthma treatment is to bring inflammatory disease under control with inhaled corticosteroids while using short and long-term bronchodilators to alleviate symptoms and improve airflow [3].

A relatively new and innovative strategy called bronchial thermoplasty (BT) has been proposed as a treatment for asthma, with the endpoints of reducing emergency room visits in those with severe persistent asthma [4-7]. BT involves the use of radiofrequency (RF) thermal energy, delivered through a bronchoscope, to reduce the mass of airway smooth muscle cells, which are thought to be responsible for bronchial constriction and resultant airflow obstruction [6,8]. While BT has been approved for the treatment of asthma, its efficacy and safety remain controversial [7]. Major concerns include the potential for thermal injury to exacerbate asthma in the acute setting, as well as thermal injury-induced narrowing of airway lumen through scar formation $[1,4,6,9-11]$.

While RF ablation is a viable option for BT, a new approach may allow for a more effective treatment without the drawbacks of existing therapies. With the use of Electroporation, we may be able to ablate the airway without the risk of thermal injury [12]. Electroporation uses direct current (DC) to apply an electric field to a cell, resulting in an increase in electrical conductivity and allowing for permeability of the cell membrane. When the applied electricity is above the cell's electroporation threshold, the cell is unable to repair its pores and will ultimately die. With the use of high voltage, one is able to eliminate cells within a distinct lesion.

We hypothesized that a non-thermal ablation approach can have the benefit of selectively eliminating airway smooth muscle cells, without the morbidity of acute airway injury or chronic airway

Correspondence to: Samuel J. Asirvatham, M.D., Professor of Medicine, Division of Cardiovascular Diseases, 200 First Street SW, Rochester, MN 55906, USA, Tel: 507-284-2511; E-mail: asirvatham.samuel@mayo.edu

Received: October 19, 2016; Accepted: November 30, 2016; Published: December 06, 2016 
stenosis. We therefore developed novel prototype devices that utilize DC electroporation energy and normal saline through a bronchoscope. This report describes the design of our devices and illustrates our preliminary proof-of-concept data.

\section{Experimental methods}

\section{Canine study preparation and monitoring}

This study was conducted in accordance with the Mayo Clinic IACUC committee for proper handling and care of animals. Experiments included two mongrel dogs, each weighing between 30-40 kilograms. Anesthesia was induced with intravenous ketamine $(10 \mathrm{mg} /$ $\mathrm{kg}$ ) and valium $(0.5 \mathrm{mg} / \mathrm{kg})$, and propofol (1-2 mg/ $\mathrm{kg} \mathrm{IV)} \mathrm{and} \mathrm{fentanyl}$ $(2 \mathrm{mcg} / \mathrm{kg} \mathrm{IV})$ were continued to maintain an adequate anesthetic plane. Core body temperature was maintained at 37 degrees Celsius using both dorsal and ventral heating pads throughout the study. Standard electrocardiographic leads were used to record electrograms on a Prucka CardioLab ${ }^{\star}$ recording system (GE Healthcare, Wauwatosa, $\mathrm{WI})$. During the procedure, Succinylcholine $(0.07 \mathrm{mg} / \mathrm{kg} \mathrm{IV})$ was given to paralyze the airways.

\section{Bronchoscopy and catheter ablation procedure}

Combined direct visualization was accomplished via bronchoscopy and fluoroscopy (Acuson Sequoia, Siemens) both to select and confirm airway location and catheter placement. A Boston Scientific EPT 1000XP Ablation generator (EP Technologies, Boston Scientific Corp) was utilized. Radiofrequency ablation was delivered for 60-120 seconds at a Power setting of 30-45 Watts. During ablation, normal saline was infused at $999 \mathrm{ml} /$ hour in order to act as a virtual electrode and provide for widespread ablation activity. During direct current (DC) ablation, power was set at 7,500 $\mu \mathrm{A}$.

Functional studies to assess airways' hyperresponsiveness were performed pre and post ablation using methacholine. After measuring the resting diameter, methacholine (Provocholine from Metaphram, Ontario, Canada) was sprayed into the airway. CT scanning was performed pre and post ablation (Siemen CT Scanner, Malvern, PA) in order to acquire 3D images of the lung parenchyma and airways. Tidal volume and positive end-expiratory pressure were constant between pre and post ablation CT image acquisition. Airway measurements were performed at selected landmarks to provide internal consistency.

Post-study, each dog was euthanized via induction of ventricular fibrillation under anesthesia using direct current to the canine heart. Post-mortem necropsy was performed and anatomic resection of the bronchial segments was completed in order to document device delivery and energy application, and evaluate for damage to critical surrounding structures.

\section{Results}

\section{Prototype design}

We developed two novel, prototypical devices to deliver DC electroporation energy to the smooth muscle of the airways. These were used to deliver both radiofrequency and DC electroporation energy to the canine airways via a bronchoscope. A total of six RF lesions and three DC lesions were delivered in total, encompassing eight segments of the lung.

An example of successful balloon ablation in the right lower lobe with RF and saline is shown (Figure 4). A second example of ablation lesion is from the superior-medial segment of the right lower lobe, but with the use of DC electroporation energy. (Refer to table 1 for energy applied and time of application).

Functional evidence of effect on smooth muscle cells in the lung was determined by measuring airway dimensions pre and post ablation, as well as the response to methacholine. We also demonstrated the reverse of the methacholine response with the use of atropine (Figure 5-6, Table 2).

\section{Discussion}

These devices were constructed to have the capability of delivering both radiofrequency and DC electroporation energy. In addition, these prototypes were designed with the capacity to deliver normal saline to the surrounding sites of contact ablation in order to function as a virtual electrode [9].

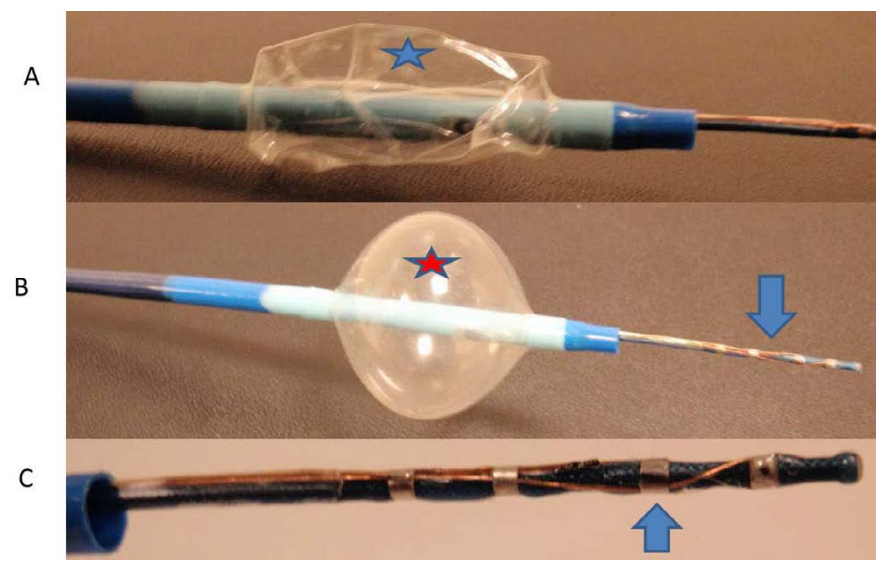

Figure 1. Prototype Single Balloon.

A. Catheter device with a deflated external balloon (star). B. Inflated balloon (star) to block saline solution from coming back, with electrode extended (arrow). C. Close up view of electrode used for DC and RF ablation.

Table 1. Ablation Settings.

\begin{tabular}{|c|c|c|c|c|c|c|}
\hline Location & & $\begin{array}{l}\text { Energy } \\
\text { Type }\end{array}$ & $\begin{array}{l}\text { Power } \\
\text { (watts) }\end{array}$ & Irrigation & Impedence & $\begin{array}{l}\text { Time } \\
\text { (sec) }\end{array}$ \\
\hline \multirow[t]{3}{*}{$\begin{array}{l}\text { 1. Left Lower Lobe } \\
\text { Anterobasal }\end{array}$} & $\begin{array}{l}\text { Ablation } \\
\text { Lesion \#1 }\end{array}$ & RF & $5-30 \mathrm{~W}$ & $\begin{array}{l}1020 \mathrm{ml} / \\
\text { hour }\end{array}$ & 104-110 & 120 \\
\hline & $\begin{array}{l}\text { Ablation } \\
\text { Lesion \#2 }\end{array}$ & RF & $10-12 \mathrm{~W}$ & $\begin{array}{l}1020 \mathrm{ml} / \\
\text { hour }\end{array}$ & $10-102$ & 50 \\
\hline & $\begin{array}{l}\text { Ablation } \\
\text { Lesion \#3 }\end{array}$ & $\mathrm{RF}$ & $10-12 \mathrm{~W}$ & $\begin{array}{l}1020 \mathrm{ml} / \\
\text { hour }\end{array}$ & 79-95 & 60 \\
\hline \multirow[t]{2}{*}{$\begin{array}{l}\text { 2. Left Upper- } \\
\text { Lingula }\end{array}$} & $\begin{array}{l}\text { Ablation } \\
\text { Lesion \#1 }\end{array}$ & DC & $1,000 \mu \mathrm{A}$ & $\begin{array}{l}400 \mathrm{ml} / \\
\text { hour }\end{array}$ & $\begin{array}{l}\text { No } \\
\text { Impedence } \\
\text { Given }\end{array}$ & 120 \\
\hline & $\begin{array}{l}\text { Ablation } \\
\text { Lesion \#2 }\end{array}$ & $\mathrm{DC}$ & $7,500 \mu \mathrm{A}$ & $\begin{array}{l}400 \mathrm{ml} / \\
\text { hour }\end{array}$ & $\begin{array}{l}\text { No } \\
\text { Impedence } \\
\text { Given }\end{array}$ & 222 \\
\hline $\begin{array}{l}\text { 3. Right Lower Lobe } \\
\text { Medial Basal }\end{array}$ & $\begin{array}{l}\text { Ablation } \\
\text { Lesion \#1 }\end{array}$ & DC & $7,500 \mu \mathrm{A}$ & $\begin{array}{l}401 \mathrm{ml} / \\
\text { hour }\end{array}$ & $\begin{array}{l}\text { No } \\
\text { Impedence } \\
\text { Given }\end{array}$ & 300 \\
\hline \multirow[t]{3}{*}{$\begin{array}{l}\text { Right Lower Lobe } \\
\text { Lateral Basal }\end{array}$} & $\begin{array}{l}\text { Ablation } \\
\text { Lesion \#1 }\end{array}$ & $\mathrm{RF}$ & $10-48 \mathrm{~W}$ & $\begin{array}{l}999 \mathrm{ml} / \\
\text { hour }\end{array}$ & $54-59$ & 120 \\
\hline & $\begin{array}{l}\text { Ablation } \\
\text { Lesion \#2 }\end{array}$ & RF & $47-50 \mathrm{~W}$ & $\begin{array}{l}999 \mathrm{ml} / \\
\text { hour }\end{array}$ & $54-55$ & 120 \\
\hline & $\begin{array}{l}\text { Ablation } \\
\text { Lesion \#3 }\end{array}$ & $\mathrm{RF}$ & $48-50 \mathrm{~W}$ & $\begin{array}{l}999 \mathrm{ml} / \\
\text { hour }\end{array}$ & $55-57$ & 60 \\
\hline
\end{tabular}

The ablation settings for all sites. 


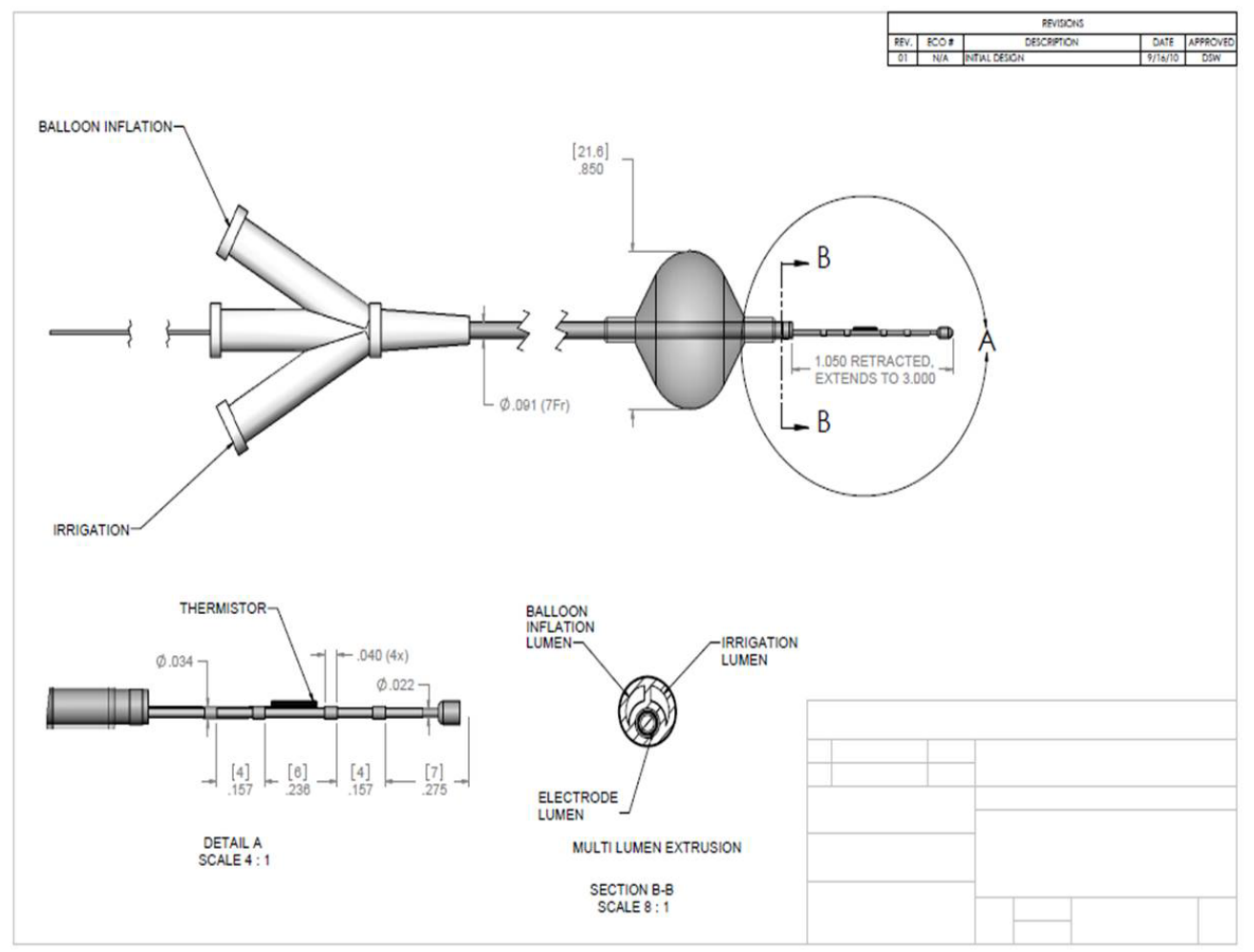

Figure 2. Balloon Catheter Lung.

Design for single balloon catheter. The size of the electrodes and spacing is 0.157-0.275 inches (star).

Table 2: Pre and Post Ablation Methacoline.

\begin{tabular}{|l|l|}
\hline $\begin{array}{l}\text { Positive Control: } \\
\text { Pre-ablation control vs Pre-ablation MCH Constricts Airways (diameter cm) }\end{array}$ & \\
\hline Location 1 & 0.84 control to 0.67 post-MCH (-23\%) \\
\hline Location 2 & 0.76 control to 0.48 post MCH (-37\%) \\
\hline $\begin{array}{l}\text { Experimental: } \\
\text { Pre-ablation MCH vs Post-ablation MCHMCH (diameter cm) }\end{array}$ & \\
\hline Location 1 & 0.76 to $1.14(+50 \%)$ \\
\hline Location 2 & 0.76 to $1.19(+57 \%)$ \\
\hline
\end{tabular}

The positive control demonstrates the efficacy of methacholine to induce bronchial constriction, in normal (pre-ablation) airways. The experiment demonstrates the effect of ablation to acutely impair the bronchoconstrictive response of $\mathrm{MCH}$, measured before and after ablation. Airway measurements made at $15 \mathrm{~cm}$ of PEEP during a breath hold at under I.V. anesthesia with neuromuscular blockade.

Figure 1 shows prototype ablation device \#1. This device consists of four electrodes, each being 0.40 inches in size, with $0.157-0.275$ inches between sequential electrodes (Figure 2). The device includes a catheter shaft embedded in a single balloon structure within an intervening lumen. These two lumens emanate from the end of the device to allow for inflation of the balloon, as well as for liquid delivery to the local tissue. The balloon can be inflated with air or saline, and continuous saline flow is set at $17 \mathrm{cc} / \mathrm{hr}$. In addition, the inflated occlusion balloon functions to prevent retrograde fluid flow.

Prototype ablation device \#2 consists of expandable nitinol mesh and electrodes embedded within this mesh (Figure 3). The electrodes were placed throughout the mesh at 0.20 inches in size and 0.10 inches between sequential electrodes. The mesh is encompassed by a dual balloon design in order to maintain a targeted fluid localization (Figure 3).

These data give support for the efficacy of electroporation based bronchial thermoplasty as a method of treatment for asthma. With

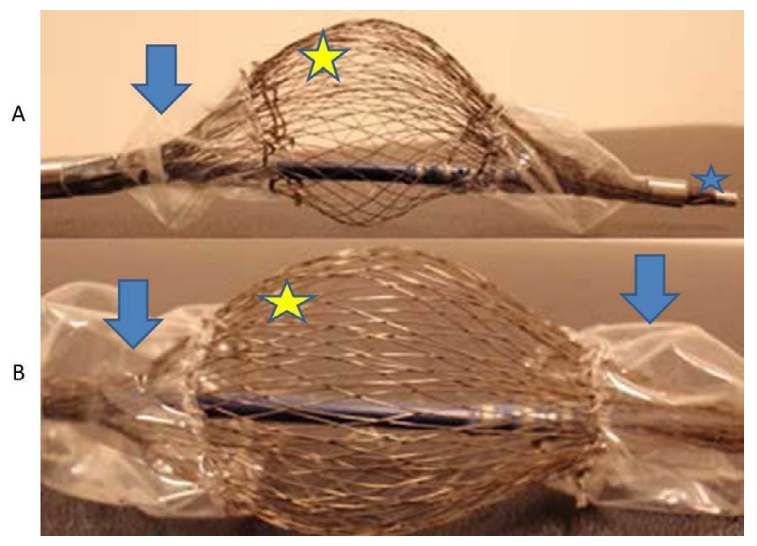

Figure 3. Prototype 2 Double Balloon with Mesh Electrodes.

A. Deflated balloons (arrows), electrodes (smily face), and deflectable tip (star). B. Close up view of electrodes (star) and deflated balloons (arrows) 


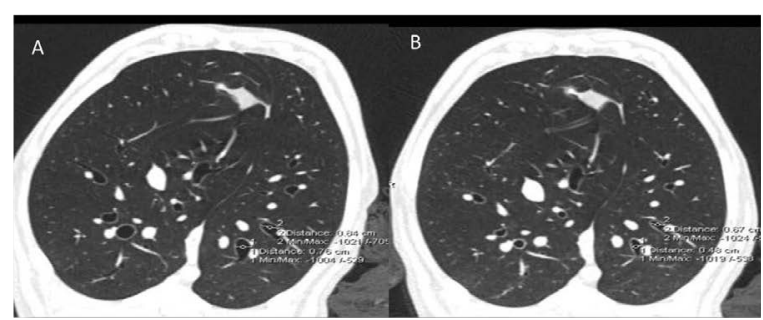

Figure 4. A. As a demonstration of the effect of our positive control (A) Methacholine dramatically Constricts airways prior to ablative intervention (B).

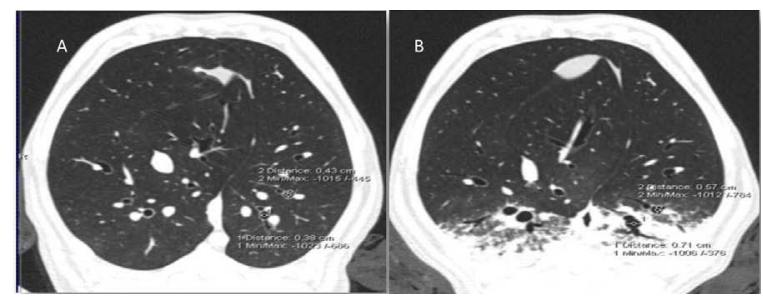

Figure 5. A. As a demonstration of the experimental effect of ablation, the response of airway constriction to $\mathrm{MCH}$ (A) is dramatically decreased following airway ablation (B).

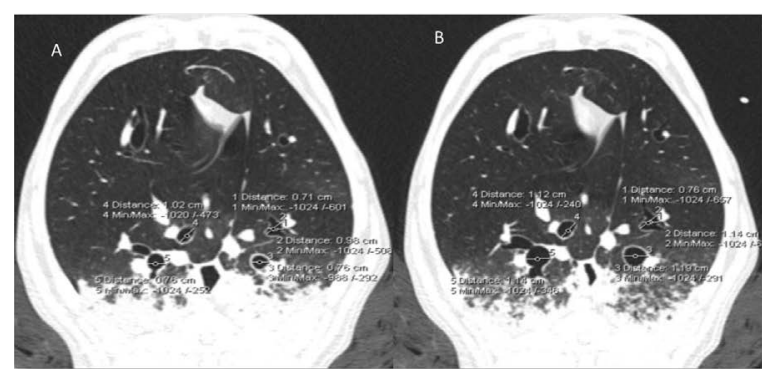

Figure 6. Post ablation, airway constriction with methacholine (A) remains reversible atropine (B), reduced constrictive response to methacholine following ablation is not due to thermal injury.

regards to the safety of this technique, the use of non-thermal DC electroporation energy showed little to no injury or scar formation in these experiments. Current BT treatment has the potential to have lung abscess and stenosis of the airways [5,6,11]. It also appeared that the prototypes used were effective in reaching more distal airways, suggesting that a virtual electrode is a potential option for treatment of these locations. Further investigation and testing are necessary to confirm these findings.

\section{Conclusion}

We report the initial findings of the feasibility of our novel devices and approach to ablate smooth muscle cells in two acute canine studies. We demonstrated visual and gross evidence of ablation using thermal RF and non-thermal DC electroporation. Due to the device's nonthermal nature, it may reduce the risk of thermal-induced stenosis seen with current RF ablation of the airways [12]. In addition, using a virtual electrode with saline elution, we were afforded the exciting opportunity to reach the lower and smaller distal airways.

While the implication of these observations remains uncertain, the advantage of allowing for smooth muscle ablation without thermal airway injury and over a greater distance has several theoretical advantages including: decreased airway swelling/stenosis, elimination of choke-points from skipped lesions, and ability to treat the entire lung in a single session. These early findings will require larger animal trials, as well as evaluation of safety and efficacy in longer duration chronic studies in order to determine applicability in human subjects. Given the current burden of disease from asthma and its limited treatment options, we believe this line of research represents an exciting and new approach to treatment.

\section{Acknowledgement}

This study was supported by NIH grant HL007111.

\section{References}

1. Trevor JL, Bhatt SP, Wells JM, et al. (2015) Benefits of completing pulmonary rehabilitation in patients with asthma. $J$ Asthma 52: 969-973. [Crossref]

2. Braman SS (2006) The global burden of asthma. Chest 130: 4S-12S. [Crossref]

3. National Asthma Education and Prevention Program (2007) Expert Panel Report 3 (EPR-3): Guidelines for the Diagnosis and Management of Asthma-Summary Report 2007. J Allergy Clin Immunol 120: S94-138. [Crossref]

4. Castro M, Rubin AS, Laviolette M, Fiterman J, De Andrade Lima M, et al. (2010) Effectiveness and safety of bronchial thermoplasty in the treatment of severe asthma: a multicenter, randomized, double-blind, sham-controlled clinical trial. Am J Respir Crit Care Med 181: 116-124. [Crossref]

5. Wheatley JR, Pare PD, Engel LA (1989) Reversibility of induced bronchoconstriction by deep inspiration in asthmatic and normal subjects. Eur Respir $J$ 2: 331-339. [Crossref]

6. Ward N (2007) Bronchial thermoplasty may improve asthma control up to 12 months after treatment. Thorax 62: 556-556. [Crossref]

7. Iyer VN, Lim KG (2014) Bronchial thermoplasty: reappraising the evidence (or lack thereof). Chest 146: 17-21. [Crossref]

8. Tsong TY1 (1991) Electroporation of cell membranes. Biophys $J$ 60: 297-306 [Crossref]

9. Leveillee RJ, Hoey MF, Hulbert JC, Mulier P, Lee D, et al. (1996) Enhanced radiofrequency ablation of canine prostate utilizing a liquid conductor: the virtual electrode. J Endourol 10: 5-11. [Crossref]

10. Müssigbrodt A, Grothoff M, Dinov B, Kosiuk J, Richter S, et al. (2015) Irrigated Tip Catheters for Radiofrequency Ablation in Ventricular Tachycardia. BioMed Research International 6.

11. Balu A, Ryan D, Niven R (2015) Lung abscess as a complication of bronchial thermoplasty. J Asthma 52: 740-742. [Crossref]

12. DeSimone CV, Kapa S, Asirvatham SJ (2014) Electroporation: Past and Future of Catheter Ablation. Circulation: Arrhythmia and Electrophysiology 7: 573-575.

Copyright: (C2016 Tri JA. This is an open-access article distributed under the terms of the Creative Commons Attribution License, which permits unrestricted use, distribution, and reproduction in any medium, provided the original author and source are credited. 